\section{Pontine reticular formation lesions: Amnestic effects on learned habits in the rat*}

\author{
ROBERT THOMPSON and THOMAS C. HENDERSON \\ Louisiana State University, Baton Rouge, La. 70803
}

Rats previously trained on two visual discrimination tasks showed profound losses in retention following small bilateral lesions placed in the region of the nucleus reticularis pontis oralis. Similar amnestic effects were obtained on a nonvisual (kinesthetic) discrimination task. These results are in marked contrast with those found in animals suffering mesencephalic reticular formation lesions.

Several investigators (Gastaut, 1958; John, 1967) have proposed that the brainstem reticular formation participates critically in learning and memory phenomena. However, recent lesion studies have failed to disclose the significance of this neural system in the performance of learned responses either in birds (Durkovic \& Cohen, 1969), rats (Kesner, Fiedler, \& Thomas, 1967; Thompson, 1969), cats (Chow \& Randall, 1964), or monkeys (Thompson \& Myers, 1971). While these results put a strain on the hypothesis that the brainstem reticular system is intimately involved in the establishment or execution of learned responses, they are by no means conclusive. For example, virtually no data exist on the influence of reticular lesions at levels below the mesencephalon on learning and memory. According to the results of the present study, small bilateral lesions of the paramedial portion of the pontine reticular formation not only abolish previously learned visual discrimination habits, but drastically impair retention of nonvisual habits as well.

\section{METHOD}

Thirteen adult male albino rats of the Wistar strain were initially trained to approach a white stimulus card and avoid an adjacent black stimulus card (brightness discrimination problem) in a Thompson-Bryant (1955) discrimination apparatus. Under the motive of escape from footshock, a response to the unlocked white card admitted $S$ to the goalbox, whereas a response to the locked black card was automatically punished by mild shock to the feet. Eight trials were given daily with an intertrial interval of 60 sec. The criterion of learning consisted of no more than one error in 2 successive days. Upon reaching the criterion of learning, the Ss were required to approach a horizontal black and white striped card and avoid a vertical black and white striped card

*This study was supported in part by USPHS Grant MH 08377 . (pattern discrimination problem), the training procedure being the same as that used for the brightness discrimination problem. Following learning of the pattern habit, five Ss sustained one-stage bilateral electrolytic lesions in the vicinity of the nucleus reticularis pontis oralis (Group NRPO), four received bilateral lesions to the overlying inferior colliculus (these Ss served as the operated control group-Group OC), and the remaining four constituted the normal control group (Group NC). After a recovery (or rest) period of 3 weeks, the Ss were given a retention test which consisted of relearning the two discrimination habits in the order in which they were originally mastered. Retention was measured in percentage error savings scores.

An additional 11 Ss were used to determine the effects of pontine reticular formation lesions on retention of a nonvisual discrimination habit. They were initially subjected to enucleation of the eyes under deep 2-day recovery period, they were trained on an incline box (kinesthetic) problem under the motive of escape from footshock to choose the arm that was inclined upward and avoid the arm that was inclined downward. Specific details of the apparatus and training procedure may be found elsewhere ( Thom pson, Lukaszewska, Schweigerdt, \& McNew, 1967). Following learning (at least 15 correct responses within 2 consecutive days), 7 Ss sustained bilateral lesions in the region of the NRPO, and the remaining 4 served as the normal control group. The retention test was given 3 weeks later and consisted of relearning the kinesthetic habit.

\section{RESULTS}

The immediate postsurgical effects of pontine reticular formation lesions were unresponsiveness and apathy. During the first postoperative week, the following behavioral disorders were observed: adipsia and aphagia, circling locomotor pattern, ataxia, obstinate progression, and hyperactivity. At the time of the chloral hydrate anesthesia. After a retention test, however, most of the "pontine" Ss appeared alert, healthy, and virtually indistinguishable from the controls.

With respect to the visual habits, all Ss of Groups NC and OC earned error savings scores on both habits in excess of $80 \%$. In contrast, four of the five Ss in Group NRPO earned savings scores below $15 \%$ on the brightness problem, and all five failed to achieve savings scores above $12 \%$ on the pattern problem. The Mann-Whitney test disclosed that Group NRPO was inferior to Group NC and Group OC in retention of both visual habits (ps $<.01$ ). No significant differences were found between the latter two groups.

Concerning the kinesthetic habit, the four control Ss earned perfect savings scores (100\%). Of the seven experimental Ss, only three were found to have lesions damaging the NRPO. These animals achieved savings scores of $9 \%, 0 \%$, and $-200 \%$. The remaining four brain-damaged Ss suffered lesions which were either ventral (in the region of the nucleus pontis and the overlying corticospinal tract) or caudal (in the region of the nucleus reticularis pontis caudalis) to the NRPO. The savings scores of these Ss ranged from $61 \%$ to $100 \%$. Statistically, the Ss with lesions of the NRPO were significantly inferior to both the control group and the brain-damaged group with inaccurately placed lesions ( $p s=.05$, Mann-Whitney U). No significant difference was found between the latter two groups.

$$
\text { DISCUSSION }
$$

All of the experimental Ss exhibiting marked amnestic effects on the visual and nonvisual discrimination habits suffered paramedial lesions of the pontine reticular formation between the levels of the decussating fibers of the brachium conjunctivum rostrally and the motor trigeminal nucleus caudally (see Fig. 1). In all cases, the NRPO was damaged bilaterally. Further evidence suggesting that damage to the NRPO is responsible for the observed retention deficits comes from the findings that lesions placed either dorsal, ventral, caudal (present study), lateral (Thompson, 1969), or medial (Craddock \& Thompson, 1971) to the NRPO have little effect on the maintenance of discriminative responses in the albino rat.

it is important to note that careful behavioral observations of our pontine Ss in the visual and kinesthetic test situations did not reveal any conspicuous disturbances in performance which might underlie the amnestic effects seen on these habits. Most of the pontine Ss were highly motivated to reach the goalbox and, 


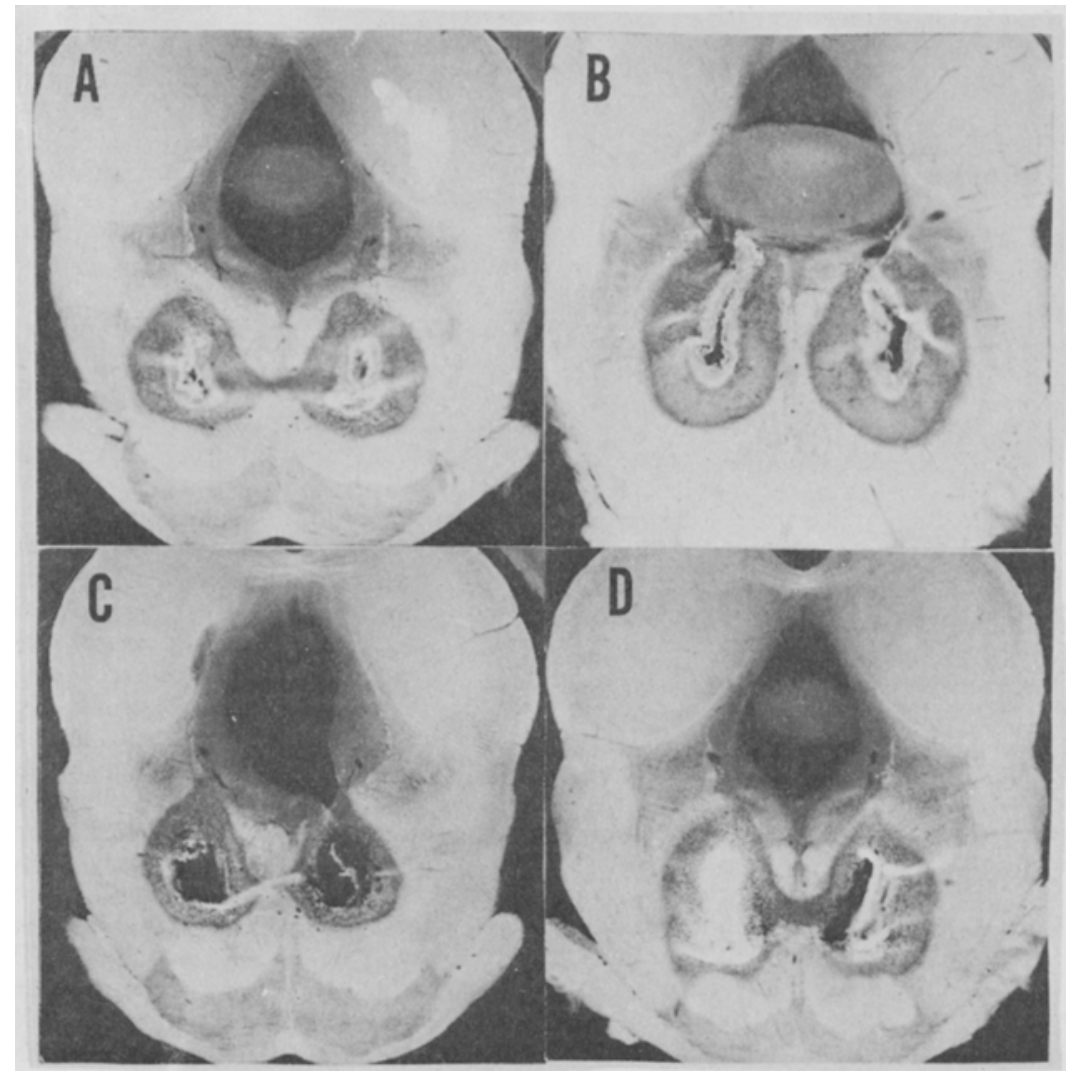

Fig. 1. Photographs of unstained sections showing lesions in the nucleus reticularis pontis oralis in three rats ( $A, B$, and $C$ ) tested on the visual discrimination problems (savings scores ranged from -171 to $11 \%$ on both habits) and one rat (D) tested on the kinesthetic discrimination problem (savings score $=0 \%$ ).

except for the first day of the retention test, oriented well to the discriminanda, made adaptive correction responses following an error, and showed no strict position habits. The fact that our Ss with NRPO lesions showed retention deficits on the pattern discrimination problem after having relearned the brightness problem militates against an explanation based upon transient disorganization of brain function (diaschisis).

The extent to which the amnestic effects induced by lesions of the NRPO can be accountable in terms of an attentional disturbance is uncertain, the mesencephalon in a rather diffuse manner. In order to interrupt a significant proportion of these cephalically directed fibers at mesencephalic levels (and therefore elicit a loss in learned behavior), it would be necessary to investigate large lesions.

\section{REFERENCES}

BRODAL, A. The reticular formation of the

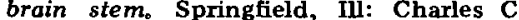
Thomas, 1958

CHOW, K. L., \& RANDALL, W. Leaming and retention in cats with lesions in reticular formation. Psychonomic Science, 1964, 1, 259-260.

CRADDOCK, S。 N., \& THOMPSON, R. A discrete interpedunculocentral tegmental region critical for retention of visual discrimination habits in the white rat. Journal of Comparative \& Physiological Psychology, 1971, 76, 39-50.

DURKOVIC, R. G., \& COHEN, D. H. Effects of rostral midbrain lesions on conditioning of heart- and respiratory-rate responses in pigeons. Journal of Comparative \& Physiological Psy chology, 1969, 68, 184-192.

GASTAUT, $H$. The role of the reticular formation in establishing conditioned reactions. In H. H. Jasper, L. D. Proctor, R. S. Knighton, W. C. Noshay, and R. T. Costello (Eds.), Reticular formation of the brain. London: Churchill, 1958. Pp. 255-272

JOHN, E. R. Mechanisms of memory. New York: Academic Press, 1967.

KESNER, R. P., FIEDLER, P., \& THOMAS, G. J. Function of the midbrain reticular formation in regulating level of activity and learning in rats. Joumal of Comparative \& Physiological Psychology, $1967,63,452-457$.

MAGOUN, H. W. The waking brain. Springfield, Ill: Charles C Thomas, 1963.

NAUTA, W. J. H., \& KUYPERS, H. G. J. M. Some ascending pathways in the brain stem reticular formation. In H. H. Jasper, L. D. Proctor, R. S. Knighton, w. C. Noshay, and R. T. Costello (Eds.), Reticular formation of the brain. London: Churchill, 1958. Pp. 3-30.

SCHEIBEL, M. E., \& SCHEIBEL, A. B. Structural substrates for integrative patterns in the brain stem reticular core. In H. H. Jasper, L. D. Proctor, R. S. Knighton, W. C. Noshay, and $R$. T. Costello (Eds.), Reticular formation of the brain. London: Churchill, 1958. Pp. 31-55.

THOMPSON, R, Localization of the "visual memory system" in the white rat Joumal of Comparative \& Physiological Psychology Monograph, 1969, 69, Part 2. 1-29.

THOMPSON, R. \& BRYANT, J. $H$. Memory as affected by activity of the relevant receptor. Psychological Reports, $1955,1,393-400$.

THOMPSON, $R$, LUKASZEWSKA, $I_{\text {, }}$ SCHWEIGERDT, A. \& MCNEW, J. J. Retention of visual and kinesthetic discriminations in rats following pretecto-diencephalic and ventral mesencephalic damage. Journal of Comparative \& Physiological Psy chology, $1967,63,458-468$.

THOMPSON, R., \& MYERS, R. E. Brainstem mechanisms underlying visually guided responses in the rhesus monkey. Journal of Comparative \& Physiological Psychology, 1971, 74, 479-512. 